\title{
Nuclear tools for characterising radiological dispersion in complex terrain: evaluation of regulatory and emergency response models
}

\section{Alastair G. Williams*, Geoffrey H. Clark and Leisa Dyer}

\author{
ANSTO Environment Division \\ Australian Nuclear Science and Technology Organisation \\ Private Mailbag 1, Menai, 2234 Australia \\ E-mail: agw@ansto.gov.au \\ E-mail: ghc@ansto.gov.au \\ E-mail: ldz@ansto.gov.au \\ *Corresponding author

\section{Richard Barton} \\ Safety and Radiation Science Division \\ Australian Nuclear Science and Technology Organisation \\ Private Mailbag 1, Menai, 2234 Australia \\ E-mail: rbz@ansto.gov.au
}

\begin{abstract}
Routine operations of a nuclear research reactor and its facilities offer opportunities for collection of rare environmental tracer datasets which can be used for atmospheric dispersion model evaluation studies. The HIFAR reactor near Sydney, Australia, routinely emits the radioactive noble gas ${ }^{41} \mathrm{Ar}$, and other radionuclides such as ${ }^{133} \mathrm{Xe}$ and ${ }^{135} \mathrm{Xe}$ are also emitted from nearby radiopharmaceutical production facilities. Despite extremely low emission levels of these gases, they are nevertheless detectable using state-of-the-art technology, and sensitive detectors have been placed at four locations in the surrounding region which features complex terrain. The high research potential of this unique dataset is illustrated in the current study, in which predictions from two atmospheric dispersion models used for emergency response are compared with ${ }^{41} \mathrm{Ar}$ peak observations from the detector network under a range of stability conditions, and long-term integrated data is also compared with a routine impact assessment model.
\end{abstract}

Keywords: routine and emergency atmospheric dispersion models; model evaluation; environmental gamma monitoring data; puff; PC-Cream.

Reference to this paper should be made as follows: Williams, A.G., Clark, G.H., Dyer, L. and Barton, R. (2005) 'Nuclear tools for characterising radiological dispersion in complex terrain: evaluation of regulatory and emergency response models', Int. J. Environment and Pollution, Vol. 24, Nos. 1/2/3/4, pp.88-103. 
Biographical notes: Dr. Alastair G. Williams is a Research Meteorologist with interests in boundary layer and micro-meteorology, turbulence and the parameterisation of subgrid processes in numerical models. He has worked as a Postdoctoral Researcher at Flinders University (South Australia), a von Humboldt Fellow at Bonn University (Germany), a Visiting Fellow at the NRC Flight Research Laboratory in Ottawa (Canada), and a Boundary Layer Turbulence Modeller at the UK Met Office. At ANSTO, Dr. Williams applies nuclear techniques to the study and prediction of atmospheric processes, and also contributes to meteorological aspects of environmental management.

Geoffrey H. Clark gained his MSc in Meteorology from the University of Melbourne, joined the Australian Atomic Energy Commission (subsequently renamed ANSTO) in 1970 and has been involved in meteorological field studies and atmospheric dispersion impact assessments at Lucas Heights and other sites around Australia. He has lead a group developing a perfluorocarbon tracer capability and more recently the installation of a network of environmental gamma monitors to evaluate atmospheric dispersion models in the complex terrain around Lucas Heights, the site of Australia's only research nuclear reactor. He has undertaken meteorological and tracer studies for the uranium mining and aluminium smelting/refining industries.

Leisa Dyer graduated with Honours for her BSc in Applied Mathematics from the University of New South Wales in 2002. Her honours year was focused on Meteorology with her thesis topic on 'Boundary Layer Flows in Tropical Cyclones.' She joined ANSTO in 2003 as a computational modeller where research has involved modelling atmospheric transport and dispersion processes on a local scale. Recently she has undertaken a large analysis evaluating the emergency response models used at ANSTO in complex terrain. Her other areas of research include climate model simulation and analysis focusing particularly on soil-vegetation-atmosphere transfer processes.

Richard Barton gained a BE in Chemical Engineering at Sydney University. In 1997, he joined ANSTO where he has gained considerable experience in dispersion modelling. He has been involved primarily in atmospheric dispersion modelling of routine and nonroutine radiological emissions, including setting up the model used for routine regulatory reporting of existing facilities at the Lucas Heights site, performing assessments of potential accident scenarios for these facilities, and has been involved with similar studies for the replacement research reactor. Additionally, he has performed studies for the Department of Foreign Affairs and Trade and the commercial smelting industry. His other professional experience has focused on risk and reliability assessment, especially HAZOP facilitation.

\section{Introduction}

Australia's national nuclear facility, managed at Lucas Heights in Sydney by the Australian Nuclear Science and Technology Organisation (ANSTO), operates a research reactor (named HIFAR, HIgh Flux Australian Reactor) used in the production of radioactive materials for a range of medical, industrial and research applications. As part of its environmental management strategy, ANSTO continuously monitors airborne 
emissions from stacks involved in its production process. A program of meteorological measurements enables estimates to be made of the downwind concentration of airborne pollutants, for computation of effective doses to individuals due to routine releases of airborne radionuclides in time-integrated models, and for input into real-time dispersion models for emergency response purposes. The modelled effective dose rates to members of the public are compared to notification levels set by ANSTO's regulating agency ARPANSA (Australian Radiation Protection and Nuclear Safety Agency).

ANSTO's emergency response system includes atmospheric dispersion model output for use in guiding the deployment of health physics survey teams in the case of an accidental release. As part of ANSTO's strategy of continual improvement in environmental management, it is planned to provide more quantitative model outputs in the future, which will facilitate better emergency management decisions. The purpose of the research program of which this study is a part of is to determine the utility of datasets obtained from a network of environmental gamma radiation monitoring stations for evaluation of atmospheric dispersion models in the region of the ANSTO site at Lucas Heights, Sydney (Australia), which is characterised by hills and valleys with some maritime influences like sea breezes. These monitoring stations provide a continuous time series of gamma radiation data that are radionuclide-specific, and for the assessment of regulatory and emergency response models to be presented here, we have chosen the unique ${ }^{41} \mathrm{Ar}$ tracer, which is only produced by the research reactor. Additionally, three-monthly radionuclide emissions of ${ }^{133} \mathrm{Xe}$ and ${ }^{135} \mathrm{Xe}$ from a nearby radiopharmaceutical production facility are used in the regulatory model, PC-Cream (Simmonds et al., 1995) and compared with the monitoring data over a one-year period.

\section{Methodology}

\subsection{Meteorological monitoring}

In order to investigate atmospheric dispersion processes in the complex terrain surrounding Lucas Heights, ANSTO has installed a network of three meteorological stations and four environmental gamma monitoring stations (Figure 1). Meteorological data have been collected since the start of site operations in the 1960s but more recently in digital form since 1991. Meteorological statistics such as average wind speed, wind direction and standard deviation of wind direction $\left(\sigma_{\theta}\right)$ are collected every 15 minutes, stored in-situ and radio-telemetred to a central location for transmission to various locations including the emergency operations centre. The meteorological data and ${ }^{41} \mathrm{Ar}$ source release data provide the inputs to the atmospheric dispersion models to be evaluated. 
Figure 1 The Lucas Heights region showing locations of meteorological and environmental gamma monitoring stations with topographic features

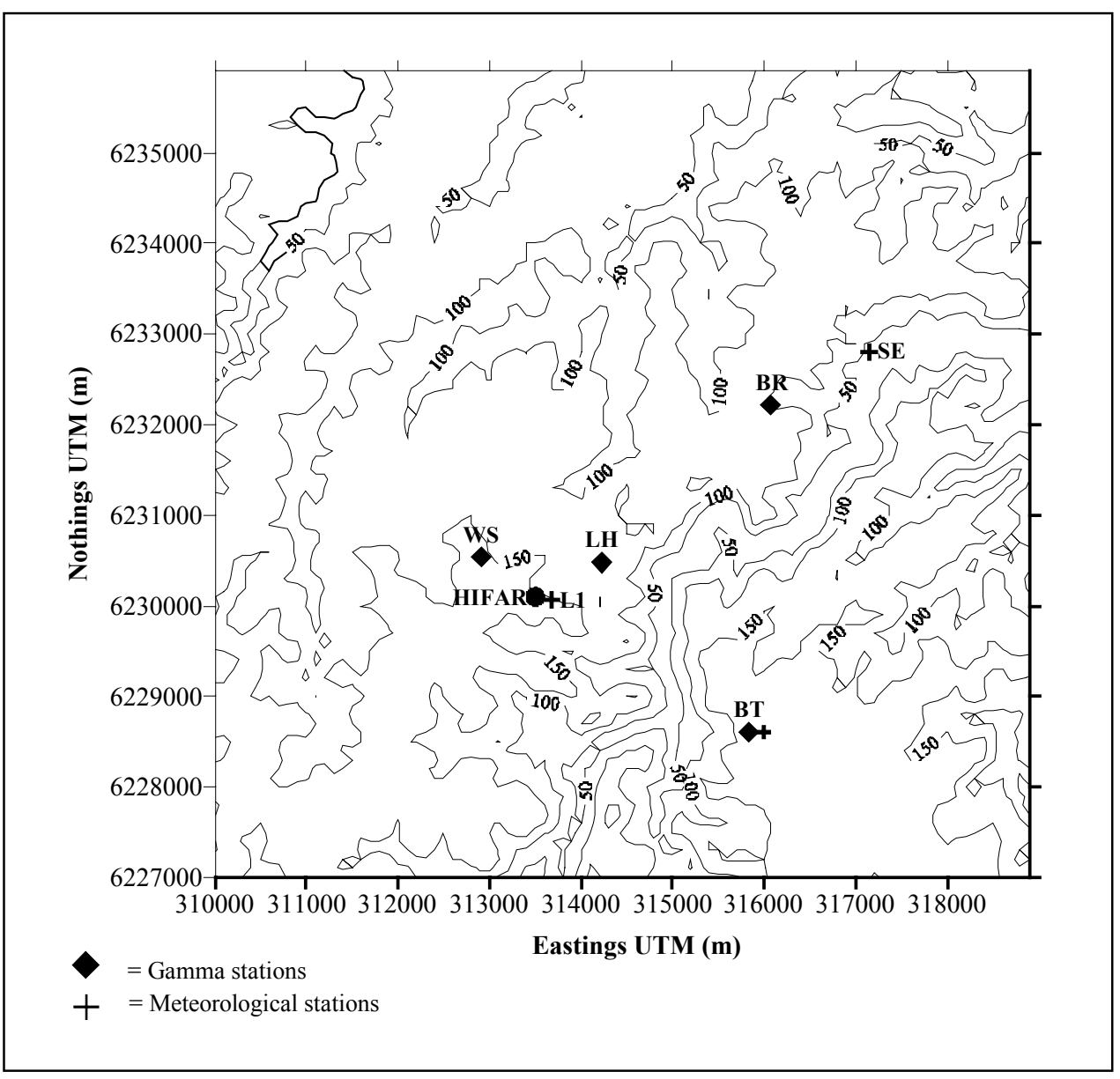

\subsection{The environmental gamma monitoring system}

The GR150 gamma radiation detection system used in this study was developed by Exploranium Canada (Grasty et al., 2001). The system allows gamma dose rates $\left(\mathrm{nGyh}^{-1}\right)$ to be collected every 15 minutes for radionuclide of interest i.e., ${ }^{41} \mathrm{Ar},{ }^{133} \mathrm{Xe},{ }^{135} \mathrm{Xe}$, skyshine, air kerma rates and the naturally occurring isotopes $\mathrm{U}, \mathrm{K}$ and Th. Background levels are calculated using local meteorological data to determine when the wind transports radionuclides from defined sources towards or away from the detectors. Case studies were chosen by identifying major peaks in the ${ }^{41} \mathrm{Ar}$ data time series from November and December 2002, and in the winter of 2003 when more stable atmospheric conditions were observed. These studies were processed for impacts at the following locations: the nearby LH gamma monitoring station $(0.82 \mathrm{~km}$ from HIFAR) and the Waste Services (WS) site $(0.73 \mathrm{~km})$; and the more distant stations at Barden Ridge (BR) $(3.33 \mathrm{~km})$, on the western side of the Woronora River Valley, and Boys Town (BT) $(2.78 \mathrm{~km})$ to the east side of the valley (see Figure 1$)$. 


\subsection{Dispersion and regulatory models}

We have evaluated two versions of the RIMPUFF (RIso Mesoscale PUFF) dispersion model (Mikkelsen, et al., 1984; Thykier-Nielsen et al., 1998) from Riso National Laboratories in Denmark. This model has been developed specifically for nuclear applications. In particular, it can be used to model dispersion of radionuclides and estimate the gamma radiation doses using calculations of gamma ray exposure from a finite size and shaped pollution cloud simulated by releasing a continuous series of puffs. The two versions of this model tested here have involved using different input wind field modules, the first being the LINCOM (LINearized COMputation) model supplied by Riso (Troen and de Bass, 1986), and the second being the NUATMOS (New version of the ATMOS1 model; Davis et al., 1984) model developed by an Australian group at Monash University (Ross et al., 1988; CAMM, 1993). The LINCOM model only uses input data from one height $(10 \mathrm{~m})$ whereas NUATMOS allows a vertical profile. To date, in order to directly compare NUATMOS with LINCOM we have only been testing with $10 \mathrm{~m}$ data. In addition, only one set of dispersion model options has been used in RIMPUFF. Specifically, the dispersion scheme simulates horizontal and vertical dispersion using a Pasquill stability category calculated with the USEPA (1987) methodology based on wind direction fluctuation standard deviations, $\sigma_{\theta}$, wind speed and time of day.

A new version of the Riso dispersion modelling system (Thykier-Nielsen et al., 2004; Mikkelsen et al., 2002; Mikkelsen et al., 1997), which integrates the wind field and dispersion calculations into one code and incorporates more modern micrometeorological scaling approaches (including Monin-Obukhov length scales) into the vertical mixing and dispersion calculations, has recently been acquired and will soon be tested as a possible replacement for the existing model. The results of the current study will therefore serve as a useful benchmark for assessment of this new model.

Environmental gamma data integrated over three quarters in 2002 and the last quarter of 2003 are also compared to estimates from the long-term radiological impact assessment model, PC-Cream (Simmonds et al., 1995).

\subsection{Case identification and classification}

The cases studied at each of the monitoring stations during winter, late autumn and early summer covered all times during the day and as a result were modelled under different atmospheric stability, wind speed and dispersion conditions. In order to assess model performance, results were grouped according to stability class and terrain complexity, with special attention being given to cases in which very poor or ambiguous agreement was found.

A plume with a finite volume containing gamma-ray-emitting radionuclides has an impact on the detector at distances up to about $300 \mathrm{~m}$. There will be maximum impact when the plume centre-line is immediately above the detector but there can also be an impact from lower concentrations of radionuclides in the fringes of the plume. Smooth, discrete-shaped peaks indicate a consistent shift in wind direction with time, causing the plume to sweep across the detector. On the other hand, erratic behaviour of the gamma monitor traces with time was also often observed (see Figure 2), usually indicating the plume striking the detector more than once as winds meandered in its vicinity. 
Figure 2 Examples of gamma radiation and model results vs wind variation (meandering wind)
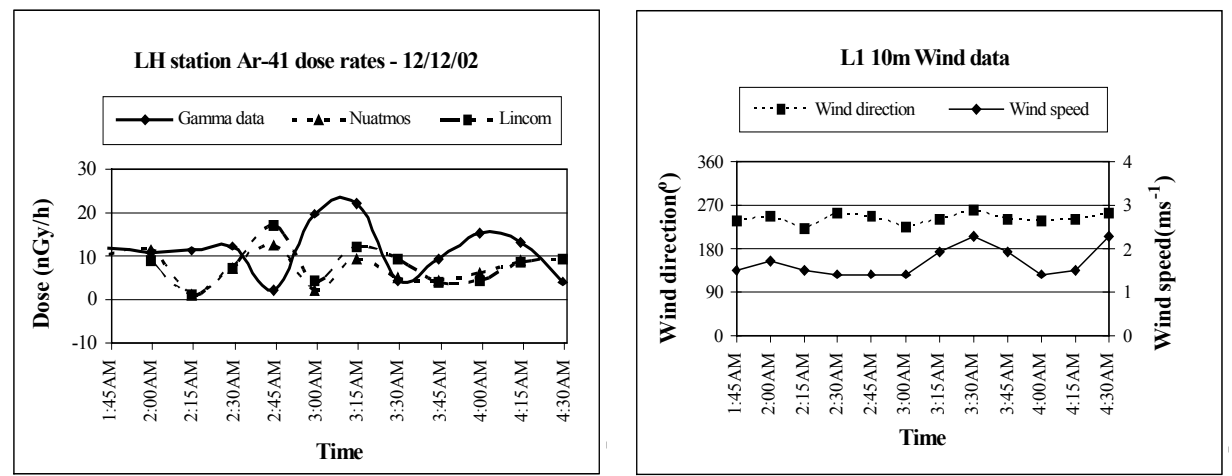

It is important to remember that the wind field models have only been tested with wind data from one altitude, usually $10 \mathrm{~m}$ or an observation corrected back to this height. The effects of both topography and wind shear can influence atmospheric dispersion processes. Therefore, in order to study topographic factors the analyses are divided into the impacts on different receptor locations. For example the LH and WS detectors are within $1 \mathrm{~km}$ of the ${ }^{41} \mathrm{Ar}$ source with only gently sloping terrain in the vicinity. The detector at BR lies further away, over a rise and down in a side gully that leads to the main Woronora River Valley. The latter valley is $100 \mathrm{~m}$ deep and lies between the source and the BT detector in the southeast that might be expected to have a different influence on the dispersion processes.

\subsection{Model evaluation techniques and recent studies}

Ratios of the model peak estimates have been calculated against those in the measured gamma data (measured: model), sometimes for two or more peaks in more complicated cases. The statistical analyses presented include the fraction of predictions within factors of two and five (FA2 and FA5), which is commonly used as an indicator of model performance, and the factor of exceedance (FOEX) as defined in Mosca et al. (1998). The FOEX ranges between $-50 \%$ and $+50 \%$, with a value equal to $-50 \%$ indicating that all the values are under-predicted whereas $+50 \%$ indicates that all values are over-predicted. The FOEX index does not take into account the magnitude of the over-prediction; it evaluates only the number of events of over-prediction. However, a quantitative estimate can be obtained by coupling the FOEX and several 'FA*' statistics (Mosca et al., 1998). A perfect model would have FA2 $=1.0$ and FOEX $=0.0$ in which case all fractions of predictions are within a factor of two of the observations, and there are exactly half under-predictions and half over-predictions.

Time differences between the occurrence of model and measured gamma peaks have also been calculated, within the limitations of the 15-minute time resolution of the systems and the fact that some observed and modelled peaks were relatively flat over several time periods. The general atmospheric stability conditions were divided into two categories: 
1 'unstable', which included Pasquill stability categories from very unstable (A) to neutral (D)

2 'stable' (E and F).

To date only a few 'stable' cases from 2003 have been analysed for station BR and a few 'unstable' cases for WS.

Canepa and Builtjes (2001) state in their methodology of dispersion model testing that out of all the statistical indices they considered, $\mathrm{FA}^{*}$ is one of the few indices that depend solely on the ratios between the measured and simulated concentrations, and not on the dataset itself. Therefore it is one of the only statistics that can be used with confidence to compare simulations of different experiments. It must be remembered, however, that the results of evaluation studies can rarely be compared unambiguously when different input datasets are used. As datasets similar to those used in the current study are rare, the comparison of our results with other recent studies in order to contrast model performance must therefore be conducted with caution.

Relevant recent studies investigating radiological species include the work by Rojas-Palma et al. (2004; see also Lauritzen et al., 2003), which also uses routine releases of ${ }^{41} \mathrm{Ar}$ to evaluate the accuracy of the atmospheric dispersion model RIMPUFF, although they concentrate on the gamma fluence rates with 10-minute data over a period of only one day. Long-range transport of airborne radioactivity over Europe as predicted by a new version of WSPEEDI (Worldwide version of System for Prediction of Environmental Emergency Dose Information) has recently been evaluated by Terada et al. (2004) using two weeks of six-hourly averaged measurements of ${ }^{137} \mathrm{Cs}$ from six European stations. WSPEEDI uses a combination of models including the atmospheric dynamic model MM5 and a Lagrangian particle dispersion model called GEARN-new. Also of interest is a new model validation database created by Hill et al. (2004) for evaluating a number of different configurations of regulatory atmospheric dispersion models from local to regional scales against daily averages of ${ }^{85} \mathrm{Kr}$ measurements. We will be concentrating on their results for local dispersion.

Recent dispersion model evaluations using nonradiological species include the study of Chang and Franzese (2003) which compares the California Puff (CALPUFF) model, the Hazard Prediction and Assessment Capability (HPAC) and the Chemical/Biological Agent Vapor, Liquid, and Solid Tracking (VLSTRACK) model using data from a recent mesoscale field campaign (Dipole Pride 26, DP26) in which 30 air samplers measured 15 min-average concentrations of $\mathrm{SF}_{6}$ over a three-hour period. However, only hourly averaged concentrations were used in their results, since CALPUFF cannot produce higher frequency data. Recent studies in complex terrain include that of Andronopoulos et al. (2004), comparing the Lagrangian atmospheric dispersion model 'Demokritos Transport code system for complex terrain' (DETRACT) against daily averages and time-integrated concentrations of ${ }^{131}$ I from 21 sampling locations over a period of four days. Finally, Canepa and Builtjes (2001) evaluate the Gaussian model SAFE_AIR against one-hourly averaged tracer concentrations measured at 28 receptors in a local area featuring complex terrain. 


\section{Results}

Statistics from the inter-comparison of measured gamma peaks and model estimates are presented in Figure 3 and discussed below. All results are calculated using data integrated over 15-minute intervals.

Figure 3 Summary statistics (15 min data) - emergency response models vs observations
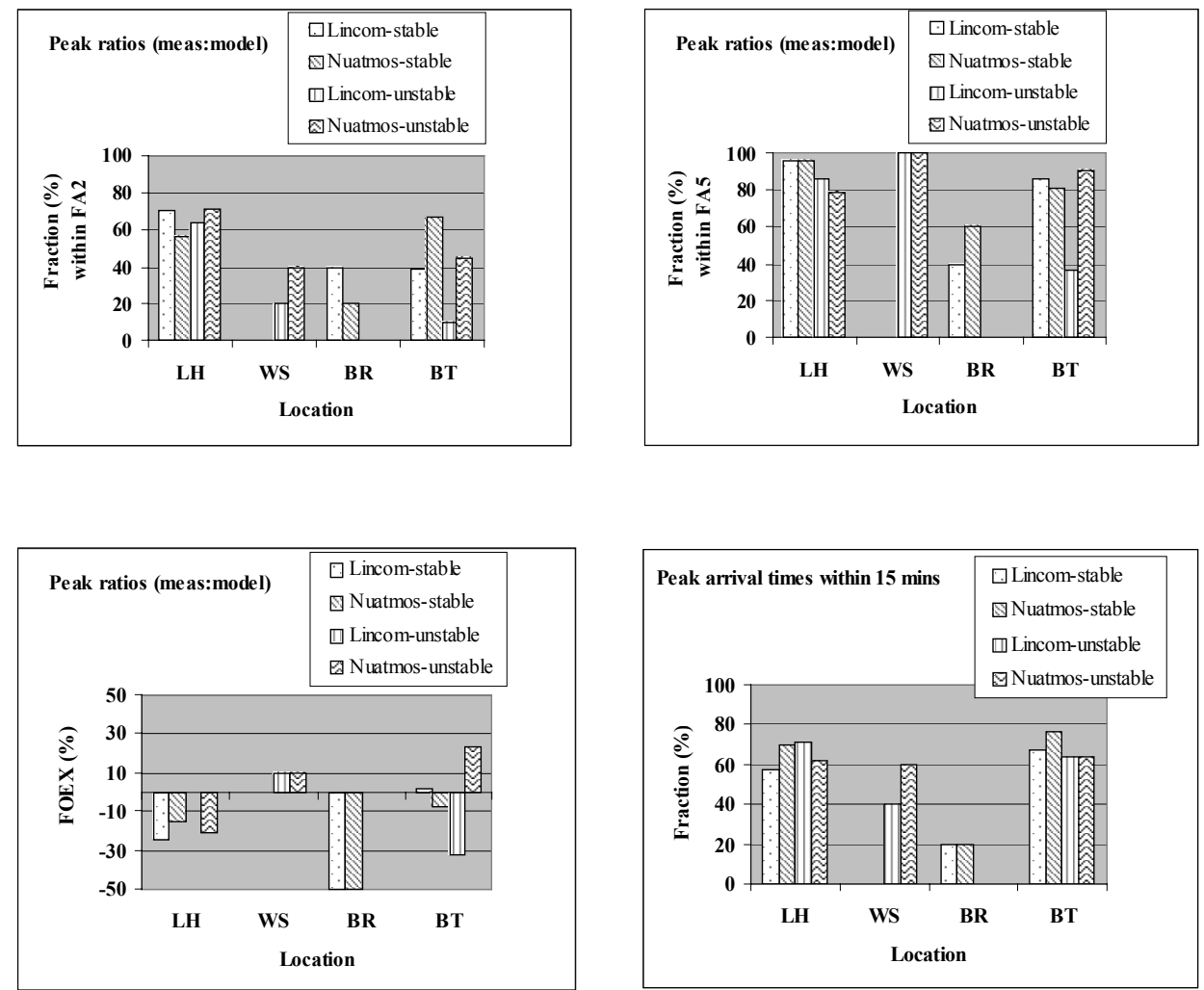

\subsection{Detectors in near-flat terrain - LH and WS}

At the near-source detector stations typified by flat or gently sloping terrain over which the ${ }^{41} \mathrm{Ar}$ plume disperses, the following can be deduced:

- The two models exhibit similar results at the LH site for all stabilities. FA2 ranges from $57-71 \%$ and FA5 from $79-96 \%$ with FOEX between 0 and $-24 \%$ and for times within 15 minutes ranging between $57-71 \%$.

- Results for the WS site are not as good for FA2 which is $20 \%$ for LINCOM/RIMPUFF and $40 \%$ for NUATMOS/RIMPUFF, but are better for FA5 with $100 \%$ and FOEX of $10 \%$ for both models and arrival within 15 minutes of $40 \%$ for LINCOM/RIMPUFF and $60 \%$ for NUATMOS/RIMPUFF. It should be noted that there was only a small sample size of five cases for WS with only unstable cases. 


\subsection{Detector in undulating terrain $-B R$}

With only a small sample of five cases, no definite conclusions can be drawn in the current study. However, it appears that both models are consistently under-predicting peak heights (FOEX of $-50 \%$ ), and only one out of the five cases arrived within 15 minutes. Slight differences between LINCOM/RIMPUFF and NUATMOS/RIMPUFF are seen in the factor analysis with FA2 and FA5 of 40\% (two out of five cases) for LINCOM/RIMPUFF and FA2 of $20 \%$ (one out of five cases) and FA5 of $60 \%$ (three out of five cases) for NUATMOS/RIMPUFF. A more detailed inspection of the wind fields that produced these results indicates that in both models the plumes were predicted to be deflected slightly to the west of the detector (Figure 4), perhaps due to local terrain influences. LINCOM/RIMPUFF also indicates stronger winds in the vicinity of the BR detector, thus producing enhanced transport and dispersion and lower predicted air concentrations and gamma radiation doses.

Figure 4 Comparison of the modelled plume behaviour near the BR station at 1706030315 EST
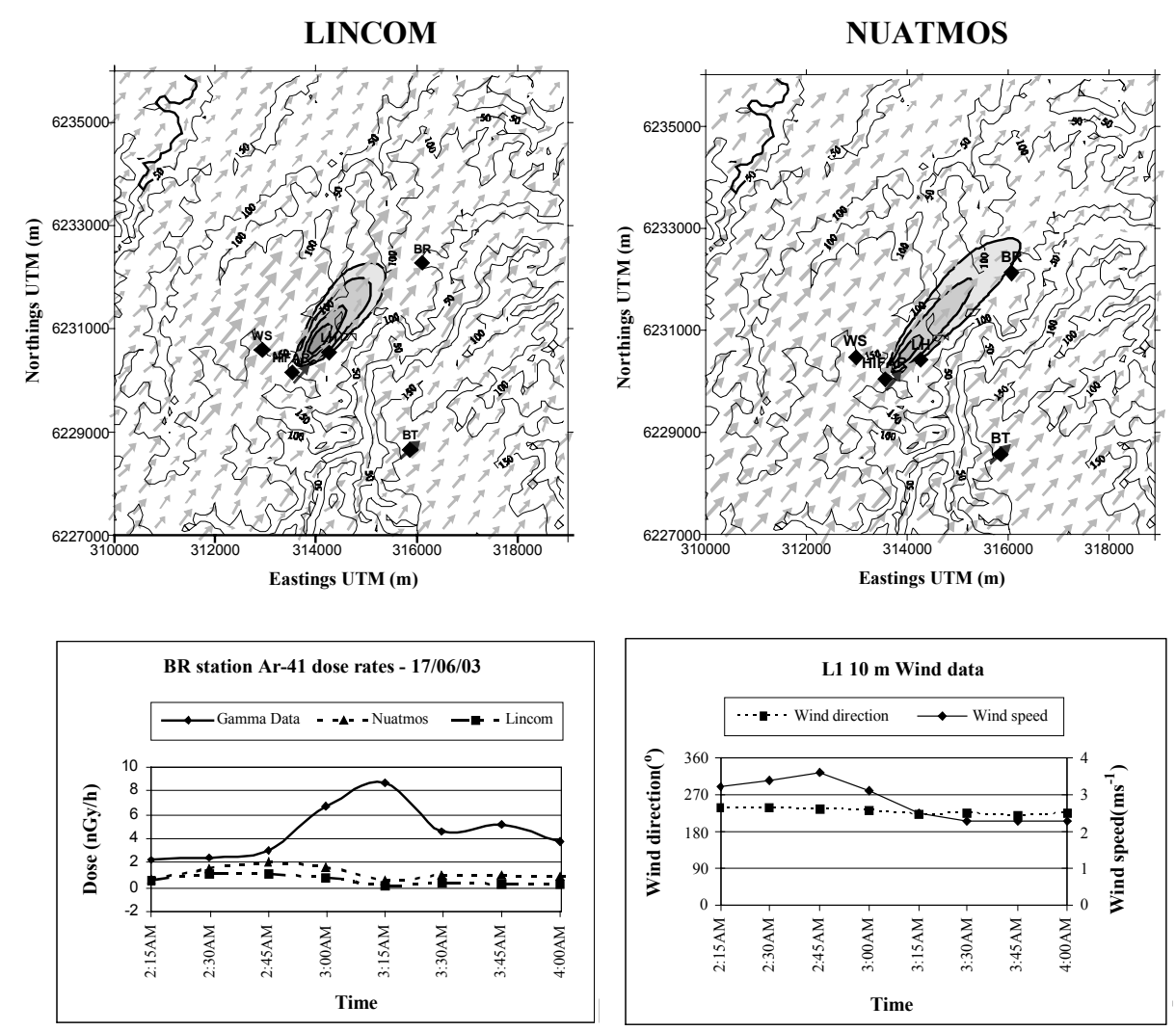
It is important to note that all five BR cases occurred in stable conditions. Protonotariou et al. (2004) has reported that strong local circulations caused significant discrepancies during stable conditions for the Urban Airshed Model (UAM), a 3D Eulerian photochemical model, when it was evaluated against observations of $\mathrm{NO}_{2}$ in an area of complex terrain and also for a suburban area near a city centre. Our detector at BR is located in a medium density housing area in undulating terrain, so it may be that plume dispersion is locally influenced by wind circulation patterns that are not predicted by the models.

\subsection{Detector in complex terrain - BT}

Previous atmospheric tracer studies using inert perfluorocarbon tracers from Lucas Heights have suggested that under morning conditions the plumes from Lucas Heights do not appear to interact strongly with the Woronora valley in cross-valley winds transporting the air-mass to the BT site (Clark et al., 2000). Peaks in the gamma radiation data at BT are regularly observed under stable atmospheric conditions.

For the current study, in the cases analysed using the environmental gamma radiation data (Figure 3), the models seem to perform best under stable conditions at BT as opposed to unstable conditions, with FA2 of $38 \%$ for LINCOM/RIMPUFF and $67 \%$ for NUATMOS/RIMPUFF (compared to $10 \%$ and $45 \%$ for unstable conditions), FOEX of $2 \%$ for LINCOM/RIMPUFF and $-7 \%$ for NUATMOS/RIMPUFF (compared to $-32 \%$ and $23 \%$ ) and higher values for times within 15 minutes of $67 \%$ and $76 \%$ (compared to $64 \%$ and $64 \%$ ), with NUATMOS/RIMPUFF performing the better of the two.

During unstable conditions, LINCOM/RIMPUFF under-predicts for most cases at BT with FOEX of $-32 \%$ and FA2 of $10 \%$ as opposed to NUATMOS/RIMPUFF which over-predicts by $23 \%$ and has FA2 of $45 \%$ and FA5 of $91 \%$, performing the better of the two again.

\subsection{Cases with poor agreement}

A number of cases were investigated in more detail when there was very poor or no agreement between the models and observations. For the LH detector, the model winds sometimes appear to be over-predicted. As the plume is expected to be relatively concentrated and narrow this close to the source, it should be noted that only a very slight offset in modelled wind directions can account for very poor performance at this site. This is consistent to findings from Canepa and Builtjes (2001) who found: 'slight differences in average wind-speed and/or direction might cause high variations in peak concentrations'.

At the WS site, distant wind stations seem to exert too great an effect on the local wind directions; when these distant stations were eliminated and only wind data used from the near source wind station, L1 (Figure 1), peaks then appeared in the model predictions. In several stable cases when the actual ${ }^{41}$ Ar plume was transported across the valley to $B T$, the modelled plumes became trapped within the valley (which had very light predicted winds). In the example shown in Figure 5, at 0630 EST the dispersion model puffs were trapped in the valley by the LINCOM winds, resulting in high concentrations there, but were then released as a concentrated 'slug' at 0645 EST to cause higher modelled doses than observed. In this case, the NUATMOS/RIMPUFF 
model gave better agreement in both the peak arrival time and intensity of the ${ }^{41} \mathrm{Ar}$ gamma dose.

Figure 5 Comparison of valley plume trapping (LINCOM) and cross-valley dispersion (NUATMOS) near the BT station under stable atmospheric conditions at
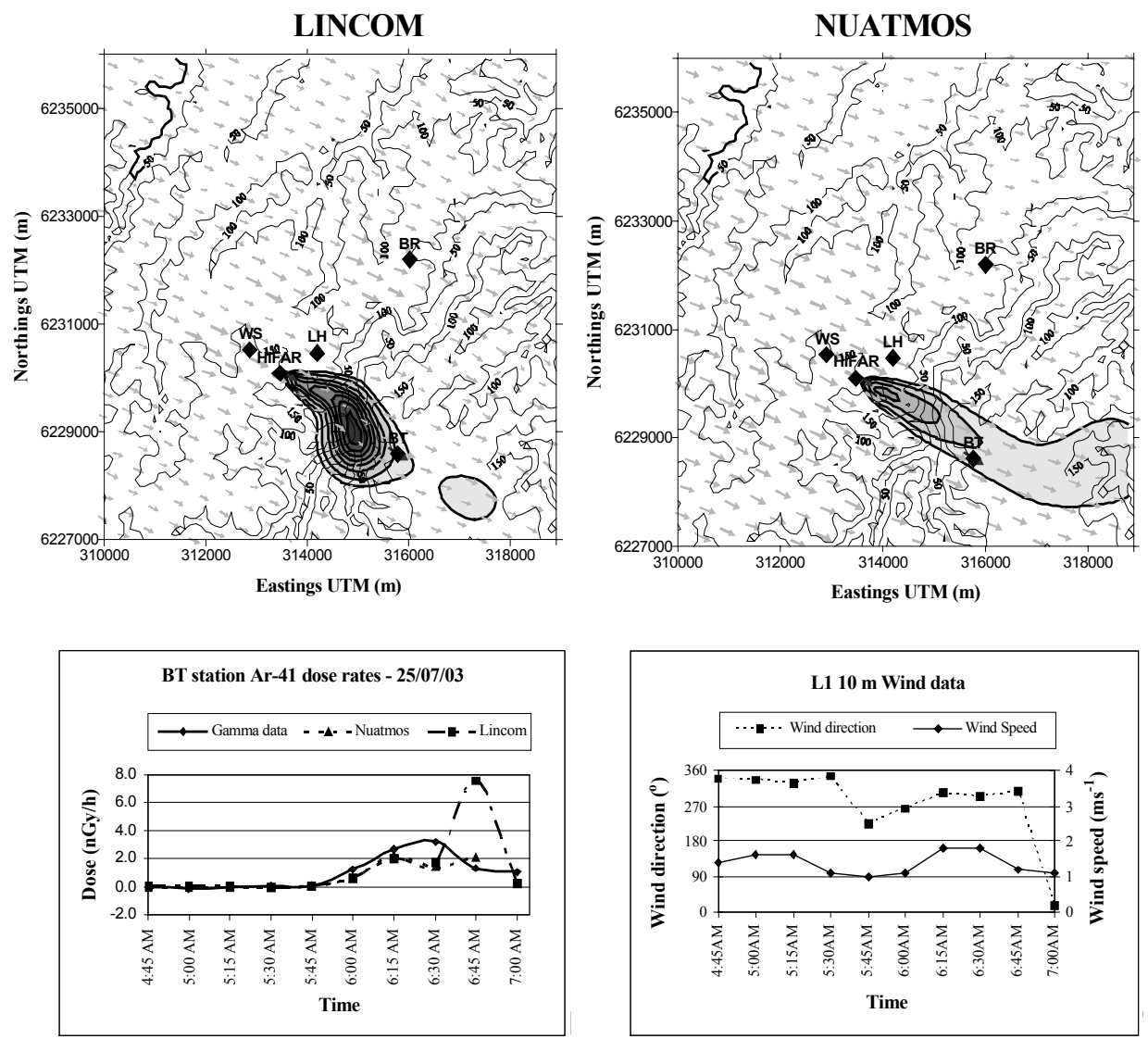

2507030630 EST

The ability of NUATMOS to use a vertical wind profile as input was found to be beneficial for unstable cases where the model performed poorly. These cases were studied in more detail by using both the $10 \mathrm{~m}$ and the $49 \mathrm{~m}$ height data from the meteorological tower at L1 as input to NUATMOS, and then varying the height at which the NUATMOS wind field was computed for subsequent input to RIMPUFF. This resulted in peaks being correctly predicted that had previously gone undetected. Using modelled winds at $10 \mathrm{~m}$ for $\mathrm{LH}$ and $20 \mathrm{~m}$ for BT provides the best comparison with the gamma data, whereas heights $>20 \mathrm{~m}$ for LH and $10 \mathrm{~m}$ heights for BT were found to perform poorly. As these results and other recent studies (Duran and Pospisil, 2004) show, the vertical shear of wind direction is a very important effect for short distances in Gaussian and Puff model predictions. Further tests of these and more recently available 
versions of LINCOM/RIMPUFF (the Local Scale Model Chain (LSMC); Mikkelsen et al., 2002) and other models are planned for the future.

\subsection{Comparison of results with recent studies}

In comparison with other recent studies on atmospheric dispersion model evaluations, both of our wind models, LINCOM and NUATMOS with RIMPUFF, produce good simulations for ${ }^{41} \mathrm{Ar}$ for the close range station LH. The FA2 values for LH range from $57-71 \%$ depending on the stability, which is very high compared with results from Terada et al. (2004) who reported only 33\% for the new version of WSPEEDI (a regional model simulation). Our models also compare well against the three models evaluated by Chang and Franzese (2003), who found FA2 results of 52\%, 60\% and $43 \%$ for CALPUFF, HPAC and VLSTRACK models respectively. However, both of these studies were conducted on much larger scales, so the current results are unsurprising. More directly comparable is the study of Rojas-Palma et al. (2004) who report under-predictions for ${ }^{41} \mathrm{Ar}$ by RIMPUFF at close range (up to $1500 \mathrm{~m}$ ). Such behaviour is only found in stable conditions at the BR site in our study and may be related to local affects as discussed earlier.

Our complex terrain station BT exhibits results that vary for differing stabilities. FA2 values from Canepa and Builtjes (2001) using SAFE_AIR (also complex terrain) range from $53-56 \%$ depending on their sampling technique and adjusted wind field parameters. NUATMOS/RIMPUFF compares favourably with these values with a FA2 of $67 \%$ for stable cases, $45 \%$ for unstable cases and FA5 of $81 \%$ for stable and $91 \%$ for unstable cases. In contrast LINCOM/RIMPUFF gives FA2 of 38\% for stable cases, $10 \%$ for unstable cases and FA5 of $86 \%$ for stable cases and $36 \%$ for unstable cases. These latter results from LINCOM/RIMPUFF are similar to the daily averaged results reported for DETRACT by Andronopoulos et al. (2004) with FA2 of 17\% and FA5 of $40 \%$ under different stabilities. Their results were improved by time-integration, with FA2 of $37.5 \%$ and FA5 of $68.8 \%$.

The two stations, WS and BR have the smallest FA2 values in our study. Our results show values of FA2 of $20 \%$ and $40 \%$ and FA5 of $100 \%$ and $100 \%$ for LINCOM/RIMPUFF and NUATMOS/RIMPUFF respectively under unstable conditions for WS and FA2 of $40 \%$ and $20 \%$ and FA5 of $40 \%$ and $60 \%$ for LINCOM/RIMPUFF and NUATMOS/RIMPUFF respectively under stable conditions for BR. These FA* values, although poorer than other cases in our study, still compare favourably against the local (within $3 \mathrm{~km}$ ) dispersion results reported by Hill et al. (2004) who have FA2 in the range $20-36 \%$ and FA5 of $48-66 \%$ for a sample size of 188 with various configurations of common regulatory models evaluated against daily averaged ${ }^{85} \mathrm{Kr}$ measurements.

\subsection{Routine release model evaluation}

The calculation of background levels of environmental gamma radiation for the radionuclides (using meteorological data) generates an average that is subtracted from the raw data to form a calibrated dataset. However, there is a standard deviation (fluctuation) associated with this average which reflects both natural variations in background levels and the intrinsic accuracy of the NaI detector. If the calibrated data are integrated over a 
sufficiently long period, the net influence of these statistical fluctuations is expected to be small (but will not be exactly zero). The three-month integrated dataset discussed below includes the effects of these statistical fluctuations.

In Table 1, data comparing the modelled and measured doses $(\mu \mathrm{Sv})$ are presented for the last three quarters of 2002 and the last quarter of 2003. Reliable environmental gamma radiation data was not available in the first three quarters of 2003 , due to instrumentation problems.

Table 1 Comparison of measured and modelled (PC-Cream) three month doses ( $\mu \mathrm{Sv})$

\begin{tabular}{|c|c|c|c|c|c|c|c|c|c|}
\hline \multirow{3}{*}{$\begin{array}{l}\text { Location } \\
\text { LH }(0.82 \mathrm{~km})\end{array}$} & \multirow{3}{*}{$\frac{\text { Radionuclide }}{{ }^{41} \mathrm{Ar}}$} & $\begin{array}{c}\text { Model } \\
\text { data }\end{array}$ & $\begin{array}{c}\text { Measured } \\
\text { data }\end{array}$ & $\begin{array}{c}\text { Model } \\
\text { data }\end{array}$ & $\begin{array}{c}\text { Measured } \\
\text { data }\end{array}$ & $\begin{array}{c}\text { Model } \\
\text { data }\end{array}$ & $\begin{array}{c}\text { Measured } \\
\text { data }\end{array}$ & $\begin{array}{c}\text { Model } \\
\text { data }\end{array}$ & $\begin{array}{c}\text { Measured } \\
\text { data }\end{array}$ \\
\hline & & \multicolumn{2}{|c|}{$2002 q 2$} & \multicolumn{2}{|c|}{$2002 q 3$} & \multicolumn{2}{|c|}{$2002 q 4$} & \multicolumn{2}{|c|}{$2003 q 4$} \\
\hline & & 1.99 & 1.83 & 1.84 & 1.53 & 0.49 & 0.73 & 0.75 & 0.36 \\
\hline & ${ }^{133} \mathrm{Xe}$ & 0.11 & 0.06 & 0.12 & 0.09 & 0.05 & 0.00 & 0.18 & 0.02 \\
\hline & ${ }^{135} \mathrm{Xe}$ & 0.15 & 0.09 & 0.15 & 0.08 & 0.07 & 0.08 & 0.16 & 0.29 \\
\hline \multirow[t]{3}{*}{ WS $(0.73 \mathrm{~km})$} & ${ }^{41} \mathrm{Ar}$ & - & - & 0.35 & 0.25 & - & - & 0.98 & 0.48 \\
\hline & ${ }^{133} \mathrm{Xe}$ & - & - & 0.00 & 0.01 & - & - & 0.02 & 0.04 \\
\hline & ${ }^{135} \mathrm{Xe}$ & - & - & 0.00 & 0.01 & - & - & 0.02 & 0.05 \\
\hline \multirow[t]{3}{*}{ BT $(2.78 \mathrm{~km})$} & ${ }^{41} \mathrm{Ar}$ & 0.18 & 0.11 & 0.19 & 0.18 & 0.08 & 0.06 & 0.08 & 0.05 \\
\hline & ${ }^{133} \mathrm{Xe}$ & 0.01 & 0.01 & 0.01 & 0.02 & 0.00 & 0.00 & 0.02 & 0.02 \\
\hline & ${ }^{135} \mathrm{Xe}$ & 0.01 & 0.00 & 0.01 & 0.00 & 0.01 & 0.00 & 0.02 & -0.02 \\
\hline
\end{tabular}

Note: A dash indicates no available data.

Three-month integrated measured doses with magnitudes less than approximately 0.05 $\mu \mathrm{Sv}$ in Table 1 were below the statistical accuracy of the method, for the reasons discussed above, and consequently cannot be considered for the purposes of this study. This includes all measured doses of ${ }^{133} \mathrm{Xe}$ and ${ }^{135} \mathrm{Xe}$ at the BT and WS sites (notably, the slightly negative value for ${ }^{135} \mathrm{Xe}$ in quarter four of 2003 at the BT site is an artefact of the background subtraction method discussed under 'Methodology'). The ${ }^{41}$ Ar release is the main contributor to annual doses from all sources at Lucas Heights. In general the modelled estimates are higher than the measured doses (i.e., more conservative), for all the modelled ${ }^{41} \mathrm{Ar}$ doses, being a maximum factor of 2.1 higher than those measured. A similar factor applies to the more significant ${ }^{133} \mathrm{Xe}$ and ${ }^{135} \mathrm{Xe}$ doses at the LH detector site.

\section{Summary}

The results of the presented studies comparing observed gamma radiation data and the emergency response models using ${ }^{41} \mathrm{Ar}$ released from a research reactor indicate the following: 
- Comparison of the environmental gamma data with estimates from two wind field models (LINCOM and NUATMOS) combined with the dispersion model RIMPUFF indicated variable performance under differing atmospheric stability and topographic influences. Both models performed well in comparison to other recent studies for the near source station LH, with LINCOM/RIMPUFF being slightly better than NUATMOS/RIMPUFF. On the other hand, NUATMOS/RIMPUFF performs significantly better than LINCOM/RIMPUFF for the across-valley (complex terrain) station BT under all stability conditions (with LIMCOM struggling to predict under unstable conditions).

- The results from comparison of long-term impacts of the routine releases using the regulatory model, PC-Cream, indicated good agreement between the model and measurements. In general for ${ }^{41} \mathrm{Ar}$, which contributes most to the annual doses in the area, the agreement is within a factor of two, with the model estimates being conservatively high.

- The time series of environmental gamma radiation data allows close investigation of various meteorological influences on dispersion in the nearby region.

- Under stable atmospheric conditions, the plume from the reactor has been frequently observed on the ridge/plateau across the valley, indicating no significant entrainment into the valley itself in agreement with previous findings of Clark et al. (2000). Further analyses are required to test if all cross-valley winds transport the plume to the ridge detector, or if some cases are entrained under certain atmospheric conditions. Another detector is to be placed further down the valley at the SE wind station site (Figure 1) to test valley entrainment mechanisms in more detail.

Given the marked variations observed in performance of the two wind field models tested here, it is clear that this site represents a challenging test for any models attempting to predict flow in complex terrain. For the stations with large amounts of data (i.e., LH and BT), good performance results for both LINCOM/RIMPUFF and NUATMOS/RIMPUFF models were found with the exception of the specific case of LINCOM/RIMPUFF under unstable conditions at BT. In the main part, these results compare well with the other recent studies mentioned here performing similar evaluations. Results from stations WS and BR appear to be poorer than the other two stations, although still in line with some recent local dispersion studies. The small sample sizes for these two stations make it difficult, however to form any strong conclusions.

As environmental gamma radiation data is now routinely sampled by ANSTO in the Lucas Heights region, much larger (statistically more significant) datasets are being generated for future model evaluation studies. These new datasets will be invaluable when testing new dispersion models for possible incorporation into the emergency response system at ANSTO, including the recently acquired state-of-the-art dispersion modelling system from Riso (Thykier-Nielsen et al., 2004; Mikkelsen et al., 2002; 1997), and the results of the current study represent a useful benchmark for this process. With ongoing collection of a continuous time series of ${ }^{41} \mathrm{Ar}$ data, and another detector planned to be deployed into the Woronora Valley in the near future, it appears that the ANSTO Lucas Heights ${ }^{41} \mathrm{Ar}$ tracer dataset is a rare and valuable resource for dispersion model evaluation exercises. 


\section{References}

Andronopoulos, S., Davakis, E., Gounaris, N., Bartzis, J. and Nychas, S. (2004) 'Dispersion modelling of radioactive pollutants: application of the DETRACT code system at the Hanford scenario', Proceedings of the 9th International Conference on Harmonisation within Atmospheric Dispersion Modelling for Regulatory Purposes, Germany: Garmisch-Partenkirchen, 1-4 June, pp.250-254.

Centre of Applied Mathematical Modelling (CAMM) (1993) 'NUATMOS (Version 6) user manual', CAMM Report, Centre of Applied Mathematical Modelling, Monash University - Caulfield Campus, 900 Dandenong Rd., Caulfield East, Victoria, No. 3.

Canepa, E. and Builtjes, P.J.H. (2001) 'Methodology of model testing and application to dispersion simulation over complex terrain', International Journal of Environment and Pollution, Vol. 16, Nos. 1-6, pp.101-115.

Chang, J. and Franzese, P. (2003) 'Evaluations of CALPUFF, HPAC and VLSTRACK with two mesoscale field datasets', Journal of Applied Meteorology, Vol. 42. No. 4, pp.453-466.

Clark, G.H., Stone, D.J.M. and Pascoe, J.H. (2000) 'Data volume of atmospheric tracer studies at Lucas Heights, NSW, Australia - 1996 to 1997', Internal ANSTO Report No. ANSTO/ED/TNOO-O1.

Davis, C.G., Brunker, S.S. and Mutschlecner, J.P. (1984) 'Atmospheric transport models for complex terrain', Journal Climate and Applied Meteorology, Vol. 23, No. 2, pp.235-238.

Duran, J. and Pospisil, M. (2004) 'Validation and comparison of dispersion models of RTARC DSS', Proceedings of the 9th International Conference on Harmonisation within Atmospheric Dispersion Modelling for Regulatory Purposes, Germany: Garmisch-Partenkirchen, 1-4 June, pp.126-130.

Grasty, R.L., Hovgaard, J. and LaMarre, J.R. (2001) 'A fence line noble gas monitoring system for nuclear power plants', Radiation Protection Dosimetry, Vol. 95, No. 3, pp.249-256.

Hill, R., Taylor, J., Lowles, I., Emmerson, K. and Parker, T. (2004) 'A new model validation database for evaluating EARMOD, NRPB R91 and ADMS using Krypton-85 data from BNFL Sellafield', Proceedings of the 9th International Conference on Harmonisation within Atmospheric Dispersion Modelling for Regulatory Purposes, Germany: Garmisch-Partenkirchen, 1-4 June, pp.64-68.

Lauritzen, B., Astrup, P., Drews, M., Jorgensen, H., Mikkelsen, T., Thykier-Neilsen, S., Aage, H., Korsbech, U., Bargholz, K., Rojas-Palma, C. and Van Ammel, R. (2003) 'Atmospheric dispersion of argon-41 from a nuclear research reactor: measurement and modelling of plume geometry and gamma radiation field', International Journal of Environment and Pollution, Vol. 20, Nos. 1-6, pp.47-54.

Mikkelsen, T., Larsen, S.E. and Thykier-Nielsen, S. (1984) 'Description of the riso puff diffusion model', Nuclear Technology, Vol. 67, pp.55-65.

Mikkelsen, T., Thykier-Nielsen, S., Astrup, P., Deme, S., Sorensen, J.H., Rasmussen, A., Pasler-Sauer, J., Schishtel, T., Raskob, W., Martens, R. and Robertsson, L. (2002) 'Functionality specification for the Local Scale Model Chain LSMC in RODOS', Report No. $\operatorname{RODOS}(W G 2)-T N(98)-03$, Available from Riso National Laboratories, Denmark.

Mikkelsen, T., Thykier-Nielsen, S., Astrup, P., Santabarbara, J.M., Sorensen, J.H., Rasmussen, A., Robertson, L., Ullerstig, A., Deme, S., Martens, R., Bartzis, J. and Pasler-Sauer, J. (1997) 'MET-RODOS: a comprehensive atmospheric dispersion module', Radiation Protection Dosimetry, Vol. 73, Nos. 1-4, pp.45-56.

Mosca, S., Graziani, G., Klug, W., Bellasio, R. and Bianconi, R. (1998) 'A statistical methodology for the evaluation of long-range dispersion models: an application to the ETEX exercise', Atmospheric Environment, Vol. 32, No. 24, pp.4307-4324. 
Protonotariou, A., Bossioli, E., Athanasopoulou, E., Dandou, A., Tombrou, M., Assimakopopoulos, V., Flocas, H. and Chelmis, C. (2004) 'Validation and inter-comparison of CALPUFF regulatory model to Eulerian models and measurements. An application over the greater Athens area, Greece', Proceedings of the 9th International Conference on Harmonisation within Atmospheric Dispersion Modelling for Regulatory Purposes, Germany: Garmisch-Partenkirchen, 1-4 June, pp.131-135.

Rojas-Palma, C., Aage, H., Astrup, P., Bargholz, K., Drews, M., Jorjensen, H., Korsbech, U., Lauritzen, B., Mikkelsen, T., Thykier-Neilsen, S. and Van Ammel, R. (2004) 'Experimental evaluation of gamma fluence-rate predictions from Argon-41 releases to the atmosphere over a nuclear research reactor site', Radiation Protection Dosimetry, Vol. 108, pp.161-168.

Ross, D.G., Smith, I.N., Manins, P.C. and Fox, D.G. (1988) 'Diagnostic wind field modelling for complex terrain: model development and testing', Journal of Applied Meteorology, Vol. 27, No. 7, pp.785-796.

Simmonds, J.R., Lawson, G. and Mayall, A. (1995) 'Methodology for assessing the radiological consequences of routine releases of radionuclide to the environment', Report by the National Radiological Protection Board, UK in Conjunction with the European Commission, EUR 15760EN.

Terada, H., Furuno, A. and Chino, M. (2004) 'Improvement of Worldwide version of System for Prediction of Environmental Emergency Dose Information (WSPEEDI), (I) new combination of models, atmospheric dynamic model (MM5) and particle random walk model GEARN-new', Journal of Nuclear Science and Technology, Vol. 41, No. 5, pp.632-640.

Thykier-Nielsen, S., Astrup, P., Deme, S. and Mikkelsen, T. (2004) LSMC and RIMPUFF, User's Guide, Riso National Laboratory.

Thykier-Nielsen, S., Deme, S. and Mikkelsen, T. (1998) 'RIMPUFF, atmospheric dispersion model version RIMDOS8, Windows NT and UNIX User's Guide', Draft, September, No. 11.

Troen, I. and de Bass, A.F. (1986) 'A spectral diagnostic model for wind flow simulation in complex terrain', Proceedings of the European Wind Energy Conference, Rome, 7-9 October.

US Environmental Protection Agency (USEPA) (1987) 'On-site meteorological program guidance for regulatory modelling applications', EPA-450, 4-87-013. 